\title{
The crystal structure of 1,12-diazaperylene, $\mathrm{C}_{18} \mathrm{H}_{10} \mathrm{~N}_{2}$
}

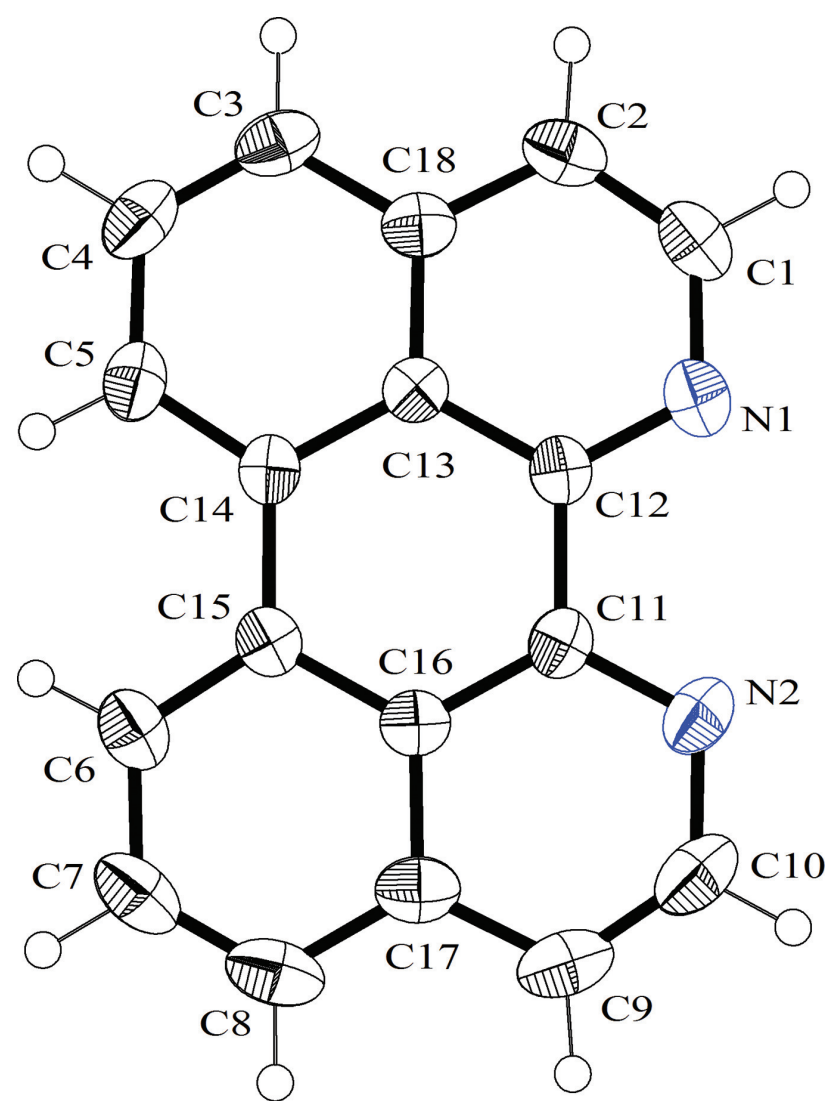

https://doi.org/10.1515/ncrs-2019-0385

Received June 3, 2019; accepted July 30, 2019; available online August 23, 2019

\section{Abstract \\ $\mathrm{C}_{18} \mathrm{H}_{10} \mathrm{~N}_{2}, \quad$ monoclinic, $P 2_{1} / c \quad$ (no. 14), $\quad a=7.9297(9) \AA$, $b=11.4021(14) \AA, \quad c=13.3572(15) \AA, \quad \beta=105.363(8)^{\circ}$, $V=1164.5(2) \AA^{3}, Z=4, R_{\mathrm{gt}}(F)=0.0325, w R_{\text {ref }}\left(F^{2}\right)=0.0774$, $T=210(2) \mathrm{K}$.}

CCDC no.: 1944261

*Corresponding author: Uwe Schilde, Universität Potsdam, Institut für Chemie, Karl-Liebknecht-Strasse 24-25, D-14476 Potsdam, Germany, e-mail: us@chem.uni-potsdam.de. https://orcid.org/0000-0002-6826-4366

Matthias Kirste, Thomas Brietzke and Hans-Jürgen Holdt: Universität Potsdam, Institut für Chemie, Karl-Liebknecht-Strasse 24-25, D-14476 Potsdam, Germany
Table 1: Data collection and handling.

\begin{tabular}{ll}
\hline Crystal: & Yellow flat needle \\
Size: & $0.30 \times 0.08 \times 0.03 \mathrm{~mm}$ \\
Wavelength: & Mo $K \alpha$ radiation $(0.71073 \AA$ A $)$ \\
$\mu:$ & $0.09 \mathrm{~mm}^{-1}$ \\
Diffractometer, scan mode: & STOE StadiVari, $\omega$ scans \\
$\theta_{\text {max }}$, completeness: & $25.0^{\circ},>99 \%$ \\
$N(h k l)_{\text {measured }}, N(h k l)_{\text {unique }}, R_{\text {int }}:$ & $20040,2051,0.055$ \\
Criterion for $I_{\text {obs }}, N\left(h k l l_{\mathrm{gt}}:\right.$ & $I_{\text {obs }}>2 \sigma\left(I_{\text {obs }}\right), 1229$ \\
$N(\text { param })_{\text {refined }}:$ & 192 \\
Programs: & SHELX [1], WinGX/ORTEP [2], \\
& PLATON [3] \\
\hline
\end{tabular}

The molecular structure is shown in the figure. Table 1 contains crystallographic data and Table 2 contains the list of the atoms including atomic coordinates and displacement parameters.

\section{Source of materials}

The title compound was synthesized by a reductive cyclization reaction of $1,1^{\prime}$-bisisoqulinoline $[4,5]$ in dimethoxyethane using potassium as reducing agent [6]. After synthesis, the residue was chromatographed on aluminium oxide with THF and concentrated under reduced pressure. For a further purification the product was dissolved in dichloromethane. This layer was washed by shaking with concentrated sodium hydroxide solution and additionally with sodium chloride brine. The clear yellow organic layer was dried with $\mathrm{MgSO}_{4}$, concentrated under reduced pressure and recrystallized from DMF. Yellow crystals ( $\mathrm{Mp} 258-260^{\circ} \mathrm{C}$ ) suitable for single crystal X-ray diffraction were obtained by slow evaporation of DMF in an airstream within 3 days.

\section{Experimental details}

The hydrogen atoms were calculated in their expected positions and refined as riding atoms with the exception of the temperature factors, which were free refined.

\section{Comment}

1,12-Diazaperylene (dap) is an established bidentate ligand. The complexes are characterized by $\pi-\pi$ stacking interactions, which often generate supramolecular assemblies, like in iridium(III) complexes with dap and 2,11-dialkylateddap [7]. Metalla-supramolecular assemblies with honeycomb 
Table 2: Fractional atomic coordinates and isotropic or equivalent isotropic displacement parameters $\left(\AA^{2}\right)$.

\begin{tabular}{lrrrr}
\hline Atom & $\boldsymbol{x}$ & $\boldsymbol{y}$ & $\boldsymbol{z}$ & $\boldsymbol{U}_{\text {iso }}{ }^{*} \boldsymbol{U}_{\text {eq }}$ \\
\hline C1 & $0.9113(2)$ & $1.03165(14)$ & $0.25918(12)$ & $0.0448(4)$ \\
H1 & 1.0266 & 1.0505 & 0.2957 & $0.045(4)^{\star}$ \\
C2 & $0.7818(2)$ & $1.10273(14)$ & $0.27236(11)$ & $0.0422(4)$ \\
H2 & 0.8081 & 1.1692 & 0.3153 & $0.053(5)^{\star}$ \\
C3 & $0.4638(2)$ & $1.14306(14)$ & $0.23109(11)$ & $0.0421(4)$ \\
H3 & 0.4827 & 1.2116 & 0.2717 & $0.054(5)^{\star}$ \\
C4 & $0.2987(2)$ & $1.10912(14)$ & $0.18233(12)$ & $0.0451(4)$ \\
H4 & 0.2037 & 1.1539 & 0.1906 & $0.051(5)^{\star}$ \\
C5 & $0.2670(2)$ & $1.00865(14)$ & $0.11996(11)$ & $0.0396(4)$ \\
H5 & 0.1509 & 0.9865 & 0.0883 & $0.050(5)^{\star}$ \\
C6 & $0.2102(2)$ & $0.80169(14)$ & $-0.02114(12)$ & $0.0428(4)$ \\
H6 & 0.1108 & 0.8418 & -0.0135 & $0.048(5)^{\star}$ \\
C7 & $0.1888(2)$ & $0.70620(15)$ & $-0.08899(13)$ & $0.0520(5)$ \\
H7 & 0.0757 & 0.6849 & -0.1275 & $0.054(5)^{\star}$ \\
C8 & $0.3279(2)$ & $0.64386(15)$ & $-0.10020(12)$ & $0.0507(5)$ \\
H8 & 0.3108 & 0.5797 & -0.1460 & $0.057(5)^{\star}$ \\
C9 & $0.6489(2)$ & $0.61343(14)$ & $-0.04973(13)$ & $0.0495(4)$ \\
H9 & 0.6392 & 0.5471 & -0.0927 & $0.060(5)^{\star}$ \\
C10 & $0.8073(2)$ & $0.65045(15)$ & $0.00631(12)$ & $0.0499(5)$ \\
H10 & 0.9055 & 0.6074 & 0.0007 & $0.054(5)^{\star}$ \\
C11 & $0.69583(18)$ & $0.80484(12)$ & $0.07775(10)$ & $0.0313(3)$ \\
C12 & $0.72404(17)$ & $0.90830(12)$ & $0.14686(10)$ & $0.0302(3)$ \\
C13 & $0.57669(17)$ & $0.97427(12)$ & $0.15639(10)$ & $0.0284(3)$ \\
C14 & $0.40181(17)$ & $0.94130(13)$ & $0.10382(10)$ & $0.0296(3)$ \\
C15 & $0.37367(18)$ & $0.83850(12)$ & $0.03483(10)$ & $0.0310(3)$ \\
C16 & $0.52216(18)$ & $0.77376(12)$ & $0.02340(10)$ & $0.0308(3)$ \\
C17 & $0.4982(2)$ & $0.67485(13)$ & $-0.04340(11)$ & $0.0390(4)$ \\
C18 & $0.60749(19)$ & $1.07544(13)$ & $0.22087(10)$ & $0.0338(4)$ \\
N1 & $0.88720(15)$ & $0.93566(12)$ & $0.19737(9)$ & $0.0406(3)$ \\
N2 & $0.83589(16)$ & $0.74497(11)$ & $0.07003(10)$ & $0.0419(3)$ \\
\hline & & & &
\end{tabular}

structures supported by $\pi-\pi$ stacking of octahedral $\mathrm{Ni}(\mathrm{II})$ and $\mathrm{Fe}(\mathrm{II})$ complexes with dap are formed, containing nanochannels [8]. Mononuclear ruthenium(II) complexes show optoelectronic properties and can bind to DNA through intercalation [9]. A further mononuclear $\mathrm{Ru}(\mathrm{II})$ complex is formed with dap and the tetradentate ligand $N, N^{\prime}$-dimethyl-2,11diaza-[3.3](2,6)-pyridinophane to complete the octahedral coordination sphere [10]. In contrast, dinuclear Ru(II) complexes are being observed with the bridging ligand 1,6,7, 12-tetraazaperylene. Mononuclear ruthenium(II) complexes with several polypyridine-type ligands - including dap were examined to act as catalysts for water oxidation [11]. Tetrahedral copper(I) complexes with 2,11-dialkylated dap exhibit low-energy MLCT transitions [12]. A dirhodium dap complex with bridging acetato groups was found to have the dual capability of intercalative and coordinative binding to DNA [13]. Formamidinat-bridged dirhodium complexes exhibit broad, strong absorption throughout the UV-visible range [14] well suited for photophysical applications. More recently, absorption and emission spectra of $\mathrm{N}$-derivatives of perylene - including dap - were simulated using a timedependent approach based on correlation functions determinated by density functional theory. The $N$-substitution can be used for fine-tuning the optical properties [15]. The complex formation of dap with transition metal ions ( $\mathrm{Fe}, \mathrm{Co}, \mathrm{Ni}, \mathrm{Cu}, \mathrm{Zn}$, $\mathrm{Ru}, \mathrm{Os}, \mathrm{Re}, \mathrm{Pd}, \mathrm{Pt}, \mathrm{Ag}, \mathrm{Cd}$ ) in the gas phase has been studied by electrospray ionization mass spectrometry $[16,17]$. Heteroleptic polymetallic $\mathrm{Ag}(\mathrm{I})$ and $\mathrm{Cu}(\mathrm{I})$ complexes were obtained and a multidentate ligand containing a large N,P,N,P,N core yielding interesting structures with $\pi-\pi$ stacked columns or discrete sixfold stacks [18].

The title compound is closely related to $1,1^{\prime}$ bisisoquinoline. Both compounds only differ by one $\mathrm{C}-\mathrm{C}$ bond, which is present in dap additionally and responsible to held the second quinoline unit in a fixed position. As a result a "large-surfaced" ligand is formed. The ring system is nearly full planar with a maximal deviation from the best plane of $0.0612(13) \AA$ (C5). The $\mathrm{C}-\mathrm{C}$ bond lengths ranges from 1.349(2) $\AA$ to 1.478(2) A. The longest bonds occur between that carbon atoms, which connect both quinoline rings. In comparison with 1,1'-bisisoquinoline (biq) the bond between the carbon atoms, adjacent to the nitrogen

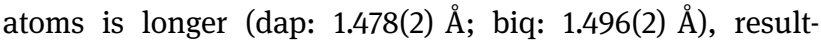
ing from the full inclusion of all $\mathrm{C}$ atoms into the aromatic ring system. The distance between both donor $\mathrm{N}$ atoms is 2.742(2) A. The crystal packing is characterized by a large number of $\pi-\pi$ interactions. Furthermore, $\mathrm{C}-\mathrm{H} \cdots \pi$ interactions are observed [C9-H9... C1-C5/C12-C14/C18/N1 ring and $\mathrm{C} 3-\mathrm{H} 3 \cdots \mathrm{Cg}$ (multiple)].

Acknowledgements: We acknowledge the support of Deutsche Forschungsgemeinschaft (German Research Foundation) and Open Access Publication Fund of Potsdam University.

\section{References}

1. Sheldrick, G. M.: A short history of SHELX. Acta Crystallogr. A64 (2008) 112-122.

2. Farrugia, L. J.: WinGX and ORTEP for Windows: an update. J. Appl. Crystallogr. 45 (2012) 849-854.

3. Spek, A. L.: PLATON - a multipurpose crystallographic tool. Acta Crystallogr. D65 (2011) 148-155.

4. Case, F. H.: The preparation of 1,1'- and 3,3'-bisisoquinoline. J. Org. Chem. 17 (1952) 471-472.

5. Grunwald, N.; Kelling, A.; Holdt, H.-J.; Schilde, U.: The crystal structure of 1,1'-bisisoquinoline, $\mathrm{C}_{18} \mathrm{H}_{12} \mathrm{~N}_{2}$. Z. Kristallogr. NCS 232 (2017) 839-841.

6. Schmelz, O.; Mews, A.; Basché, T.; Herrmann, A.; Müllen, K.: Supramolecular complexes from CdSe nanocrystals and organic fluorophors. Langmuir 17 (2001) 2861-2865. 
7. Kammer, S.; Starke, I.; Pietrucha, A.; Kelling, A.; Mickler, W.; Schilde, U.; Dosche, C.; Kleinpeter, E.; Holdt, H.-J.: 1,12Diazaperylene and 2,11-dialkylated-1,12-diazaperylene iridium(III) complexes $\left[\operatorname{Ir}\left(\mathrm{C}^{\wedge} \mathrm{N}\right)_{2}\left(\mathrm{~N}^{\wedge} \mathrm{N}\right)\right] \mathrm{PF}_{6}$ : new supramolecular assemblies. Dalton Trans. 41 (2012) 10219-10227.

8. Kammer, S.; Müller, H.; Grunwald, N.; Bellin, A.; Kelling, A.; Schilde, U.; Mickler, W.; Dosche, C.; Holdt, H.-J.: Supramolecular assemblies with honeycomb structures by $\pi-\pi$ stacking of octahedral metal complexes of 1,12-diazaperylene. Eur. J. Inorg. Chem. 2006 (2006) 1547-1551.

9. Chouai, A.; Wicke, S. E.; Turro, C.; Bacsa, J.; Dunbar, K. R.; Wang, D.; Thummel, R. P.: Ruthenium(II) complexes of 1,12diazaperylene and their interactions with DNA. Inorg. Chem. 44 (2005) 5996-6003.

10. Brietzke, T.; Mickler, W.; Kelling, A.; Schilde, U.; Krüger, H.-J.; Holdt, H.-J.: Mono- and dinuclear ruthenium(II)-1,6,7, 12-tetraazaperylene complexes of $N, N^{\prime}$-dimethyl-2,11-diaza [3.3](2,6)-pyridinophane. Eur. J. Inorg. Chem. 2012 (2012) 4632-4643.

11. Tseng, H.-W.; Zong, R.; Muckerman, J. T.; Thummel, R.: Mononuclear ruthenium(II) complexes that catalyze water oxidation. Inorg. Chem. 47 (2008) 11763-11773.

12. Kammer, S.; Kelling, A.; Baier, H.; Mickler, W.; Dosche, C.; Rurack, K.; Kapp, A.; Lisdat, F.; Holdt, H.-J.: 2,11-Dialkylated 1,12-diazaperylene copper(I) complexes: first supramolecular column assemblies by $\pi-\pi$ stacking between homoleptic tetrahedral metal complexes, exhibiting low-energy MLCT transitions. Eur. J. Inorg. Chem. 2009 (2009) 4648-4659.
13. Kang, M.; Chouai, A.; Chifotides, H. T.; Dunbar, K. R.: 2D NMR spectroscopic evidence for unprecedented interactions of cis- $\left[\mathrm{Rh}_{2}(\mathrm{dap})\left(\mu-\mathrm{O}_{2} \mathrm{CCH}_{3}\right)_{2}\left(\eta^{1}-\mathrm{O}_{2} \mathrm{CCH}_{3}\right)\left(\mathrm{CH}_{3} \mathrm{OH}\right)\right]\left(\mathrm{O}_{2} \mathrm{CCH}_{3}\right)$ with a DNA oligonucleotide: combination of intercalative and coordinative binding. Angew. Chem. Int. Ed. 45 (2006) 6148-6151.

14. White, T. A.; Duunbar, K. R.; Thummel, R. P.; Turro, C.: Electronic influences of bridging and chelating diimine ligand coordination in formamidinate-bridged $\mathrm{Rh}_{2}(\mathrm{II}, \mathrm{II})$ dimers. Polyhedron 103 (2016) 172-177.

15. Xiong, T.; Wlodarczyk, R.; Saalfrank, P.: Vibrationally resolved absorption and fluorescence spectra of perylene and $\mathrm{N}$ substituted derivatives from autocorrelation function approaches. Chem. Phys. 515 (2018) 728-736.

16. Starke, I.; Kammer, S.; Grunwald, N.; Schilde, U.; Holdt, H.-J.; Kleinpeter, E.: Complexation of diazaperylene and bisisoquinoline with transition metal ions in the gas phase studied by electrospray ionization mass spectrometry. Rapid Commun. Mass Spectrom. 22 (2008) 665-671.

17. Starke, I.; Koch, A.; Kammer, S.; Holdt, H.-J.; Möller, H. M.: Electrospray mass spectrometry and molecular modeling study of formation and stability of silver complexes with diazaperylene and bisisoquinoline. J. Mass Spectrom. 53 (2018) 408-418.

18. Attenberger, B.; El Sayed Moussa, M.; Brietzke, T.; Vreshch, V.; Holdt, H.-J.; Lescop, C.; Scheer, M.: Discrete polymetallic arrangements of $\mathrm{Agl}$ and $\mathrm{Cul}$ ions based on multiple bridging phosphane ligands and $\pi-\pi$ interactions. Eur. J. Inorg. Chem. 2015 (2015) 2934-2938. 